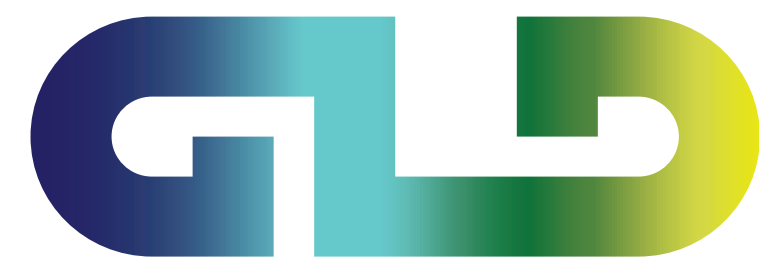

The Program on Governance and Local Development at Gothenburg

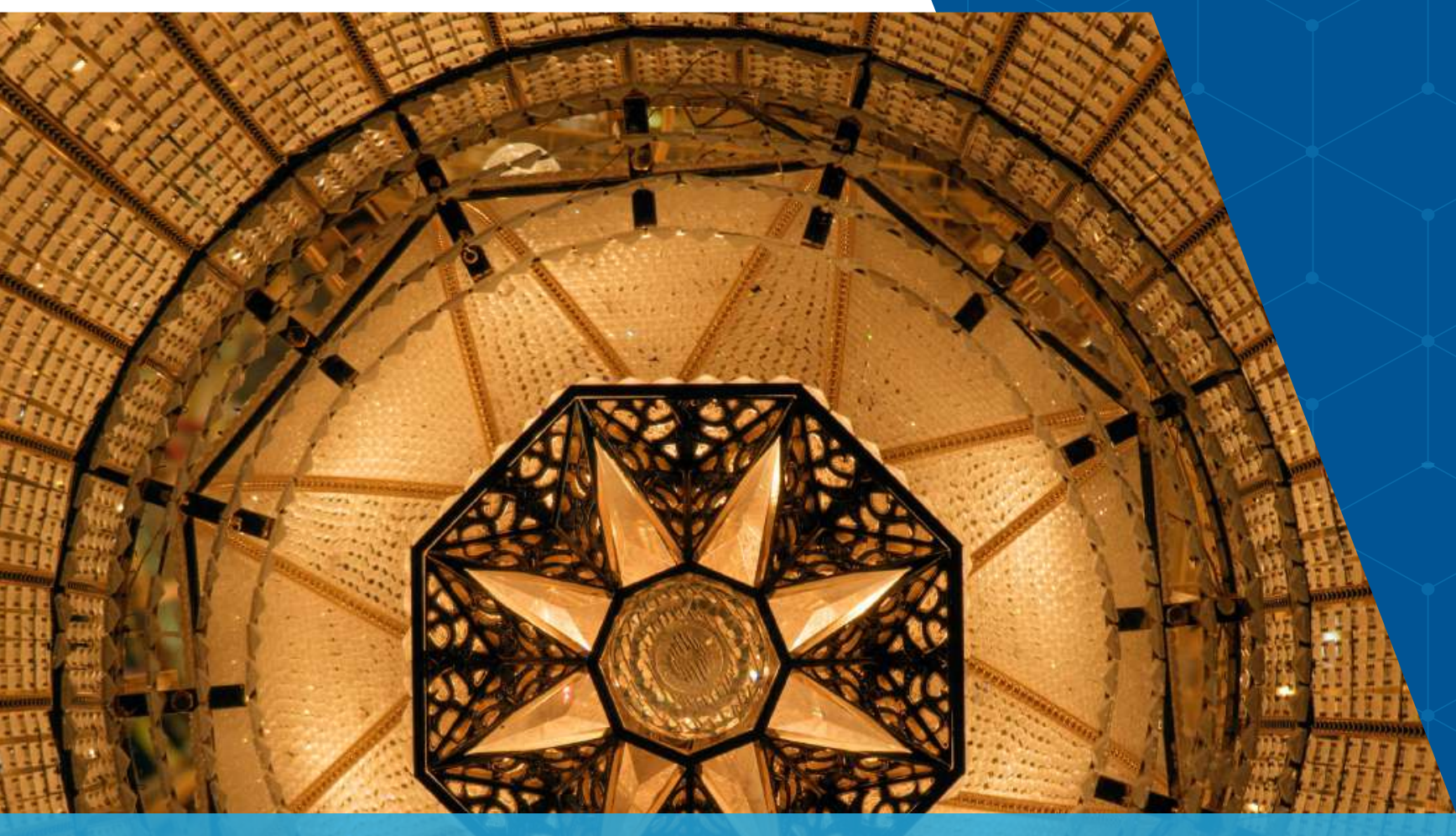

\title{
Power and Process: Decentralisation in Oman
}

\section{James Worrall}

Working Paper

No. 322020 
Front Cover: Sultan Qaboos Grand Mosque, Muscat, Oman (Mostafa Meraji, Unsplash) 


\title{
Power and Process: Decentralisation in Oman
}

GLD Working Paper:: June 2020.

\author{
James Worrall \\ School of Politics \& International Studies, University of Leeds \\ j.e.worrall@leeds.ac.uk
}




\begin{abstract}
Decentralisation has been a feature of Omani life since the early 1990s, yet while the Sultanate has been influenced by orthodox thinking around these processes its particular history, culture, circumstances, as well as its strongly centralised state have all meant that it has not simply followed this orthodox thinking. Instead, it has created a system of what this paper terms controlled-hybrid-decentralisation which manifests across four different areas within the state, and for two main purposes: efficiency and legitimacy. Both of which reinforce the power of the central state whilst maximising potential benefits from these processes. In this sense, the Omani experience of decentralisation is hybrid not only in the way it is deployed but it is also a mixture of technocratic and neo-liberal solutions combined with traditional elements of rule. It is ultimately designed to maintain the ruling bargain and uphold the power of the Omani state and dynastic system, thus being more concerned with processes and power than decentralisation itself.
\end{abstract}

Keywords: Oman, decentralisation, power, dynastic rule, controlled-bybrid-decentralisation, technocratic solutions 


\section{Introduction}

The World Bank ranks Oman among the most centralised countries when it comes to fiscal concerns (Ivanyna and Shah, 2012). Oman is classically seen as a highly centralised state, with the metropolis of Muscat dominating the political, economic and social life of the country. This centralising tendency is partly due to the nature of Sultanic rule in the country, in which the key positions of power and influence were held by Sultan Qaboos himself until his death in January 2020, and which and continues under his successor Sultan Haitham today; many decisions are therefore subject to the personal approval of the ruler. Nonetheless, Oman currently has three tiers of administration: the Central State, Governorates and Wilayats (See Figures 1 and 2) and thus has a fairly long, but relatively shallow, history of decentralisation that exhibits different characteristics and is cautious and rather tentative in its application at times. The logic of centralisation in Oman, driven both by the need to create new structures of the state from the early 1970s and the desire to avoid a return to its history of internal conflict therefore creates clear path dependencies towards centralisation, and means that decentralisation processes are less visible than in other cases in the region.

Over the past three decades, Oman has actually experienced a diversity of forms of decentralisation, both inside and outside of these existing tiers of administration. This paper explores these forms of decentralisation and argues that Oman is not following any of the more common decentralisation processes that have been pushed by international donors, both in the Middle East and beyond. Rather, it is following its own path of what this paper terms controlledbybrid-decentralisation, which enables and reinforces a strong central state while also pursuing gains in the efficiency and the legitimacy of that state though forms of decentralisation.

In developing its form of controlled-hybrid-decentralisation, the Omani state seeks to balance competing interests, challenges and opportunities to carefully manage change, given the Sultanate's history and the current realities it faces. Oman's combination of a strong state and a society traditionally based on the principle of shura (consultation and consensus building) (Rabi, 2002, pp. 41-50; Ghubash, 2006) combine to create a specific environment in which decentralisation takes place. The latter might mean that the country is potentially well-placed to further develop elements of decentralisation in its politics in the coming decades. This seeming contradiction between a strong state and a social structure, which historically has been based on debate and consensus-building, underpins another key observation of this paper; alongside the four forms of decentralisation seen in the Sultanate, there are also two notions of decentralisation. One is driven by the Sultan relinquishing, or more often delegating, powers (what might be understood as delegation as 
efficiency). The second is linked to decentralisation being about collecting ideas and opinions and thus of the state's (and ultimately the Sultan's) responsiveness to the needs of groups and individuals (or what might be understood as decentralisation as legitimacy building).

The paper begins by briefly exploring the rationales for decentralisation in the Sultanate before exploring the specific forms and processes implemented in Oman in more detail. By exploring these forms in four core areas: municipalities, privatisation, the creation of new authorities and the devolution of responsibilities within existing administrative structures, we can see the complex web of different forms of decentralisation we can understand the contingent and overlapping tools that are being used to achieve core state objectives under the wider banner of decentralisation. While some of these forms do not immediately seem to fit the stock definition of decentralisation and may, to an extent, be considered forms of deconcentration (Zsamboki and Bell, 1997, pp. 177-186), this paper argues for a more holistic view of decentralisation as a process in the Sultanate. This paper then addresses the challenges facing decentralisation in the country, focusing on opponents, variations across the country and administrative challenges. The paper concludes with an assessment of the processes in Oman and argues that decentralisation must be understood through Omani contexts and frames rather than pre-existing models from both the academic literature or other, even Middle Eastern, contexts.

\section{Why Decentralisation?}

The goals of decentralisation in Oman follow similar logics to that seen elsewhere, primarily driven in large measure by perceived efficiency and legitimacy gains. These can be seen in terms of 1 ) reducing latency in responses to problems 2) improved management of waste and expenditures and 3) greater connectivity of producers and users. These factors enhance legitimacy at all levels through a combination of efficiency of delivery and participation in process design. One should not be especially surprised that the decentralisation process in Oman really began under the fifth five year plan drawn up in 1995 and which ran from 1996-2000. After a decade of low oil prices during the 1980s, the fourth five year plan experienced difficulties with revenues meeting expenditures, leading to the following five year plan seeking both economic diversification and at the same time to trim expenditures and make savings, with the aim to invest in more productive or strategic areas instead. Having been unable to finance some intended projects in the previous plan, the Omani government sought support from the World Bank and IMF (Treichel and Mansur, 1999). Indeed, in 1994 the Omani government adopted the World Bank Revised Standard Model as its tool for understanding economic trajectories, demonstrating the influence of economic orthodoxy on the Sultanate. It is, therefore, unsurprising, given the prominence of decentralisation 
processes pursued by the international expert community and International Financial Institutions, that decentralisation was tentatively pursued by the Omani state during this period. It was also at this stage that the five year plans formally came under the wider umbrella of a guiding vision document - Oman 2020 - which had begun to be developed in the early 1990s. Given the existing preponderance of centralised decision making, decentralisation itself clearly runs against the wider centralising tendencies which are inherent in the Omani statebuilding process. However, it is clear that the influence of experts on the process was significant, as elements of decentralisation were gradually introduced into Omani policy from the mid-1990s. There is thus both an element of acceptance and resistance to decentralisation built into the DNA of the state which are pushed by contrasting influences. This dichotomy was clearly embodied in the person of Sultan Qaboos himself.

\section{Decentralisation Processes in Oman}

In reality, because of these pre-existing tendencies, decentralisation in the Omani context is not a political process but is instead driven by legal-rational demands and is controlled by webs of regulations and a step by step approach. This also means that, for a number of reasons, decentralisation has a different face in Oman than elsewhere and remains a balancing act between the devolution of power, continued oversight and expressions of control. This balancing act is crucial given the country's history of fragmentation and the Sultan's desire to keep the state on course towards his goals. Omani history has many incidences where internal divisions consistently undermined the power of the state and led to internal strife and poverty. This of course was the case up to the 1970s and the commencement of the an-nadha (renaissance) process under Qaboos, following his overthrow of his father in July 1970. These tensions therefore require something of a reconceptualisation of the term decentralisation within both the Gulf and Omani contexts.

Given that decentralisation in Oman is driven by economic necessity and external influences, yet also clashes clashing with the strong centralising tendency, the process must balance these competing demands. Decentralisation processes are always influenced by local political dynamics, but Oman remains a particularly interesting case, as its process remains relatively limited. One can, however, readily identify four main forms of decentralisation pursued by the Omani state over the past 25 years. The first of these is a more conventional form of working with and through municipalities and local government that have seen limited but important developments over the years. The second process is seen in the emergence of joint ventures, a process that has recently been driven by a necessity driven, in part but by no means exclusively, to raise revenues to cover recent worrying budget deficits, towards more innovative forms of public private partnerships and 
part-privatisations. The third element can be found in the creation of new authorities in key strategic areas, developed within the Vision documents and the five year plans but also more noticeably in the rise of free and industrial zones. The final element can be seen in the push towards the devolution of power down to the frontline within existing governmental structures. It is worth spending a little time briefly examining these forms of decentralisation that, both individually and as a collective, form an interesting amalgam of what might be termed controlled-bybrid-decentralisation.

\section{Municipalities}

In terms of local government, municipalities in Oman are usually seen as mere branches of their controlling ministry (United Cities and Local Government and World Bank, 2008, p. 222). In reality, the picture is more complex. Muscat Municipality is the largest and most well-organised in the country; it pioneers the use of new technologies and is known for its efficiency. In March 1984, the Municipality was transferred to come directly under the authority of the Diwan of the Royal Court. This was effectively an upgrade in status and provided the municipality with a clear boost from direct royal patronage. It also came with increased responsibilities, such as control over roads and bridges, street lighting and housing, were transferred to the municipality from various ministries (Muscat Municipality: Brief History, n.d.). Muscat Municipality, alongside Dhofar Governorate, were the only two local government areas to fall directly under the authority of the Diwan, rather than the Ministry of Regional Municipalities and Water Resources. In the aftermath of the Arab Spring, given the prominence of Sohar as the epicentre of demonstrations, the city's municipality was soon also brought under the wing of the Diwan, joined more recently by Musandam.

One of the major reforms announced in the slew of measures that followed the outbreak of protests around the Sultanate early in 2011 was the introduction of elections for Governorate Councils (see Figure 1). The protests in Oman, connected to the wider Arab Spring, demanded reform rather than radical change in government in the country. They primarily focused on socioeconomic issues but also included requests for governance reforms of various kinds (Worrall, 2012). Alongside giving enhanced powers to the parliament (Majlis as-Shura), it was relatively easy to bring democracy to the municipal level. These important local government reforms replaced the previously appointed members of these councils, selected by the regional governors and walis (See Figure 2 for wilayats), with elected members. The elections happened on 22 December 2012, remarkably quickly after the announcement of the reform in the Spring of 2011 (Worrall, 2015). Interestingly, employees of ministries are disbarred from standing for the position of councillor on these new bodies. Most municipalities have, however, received few new powers, such as control 
over parking fines and those municipalities that remain under the authority of the ministry remain tightly bound bureaucratically in the ways in which they exercise existing powers. 

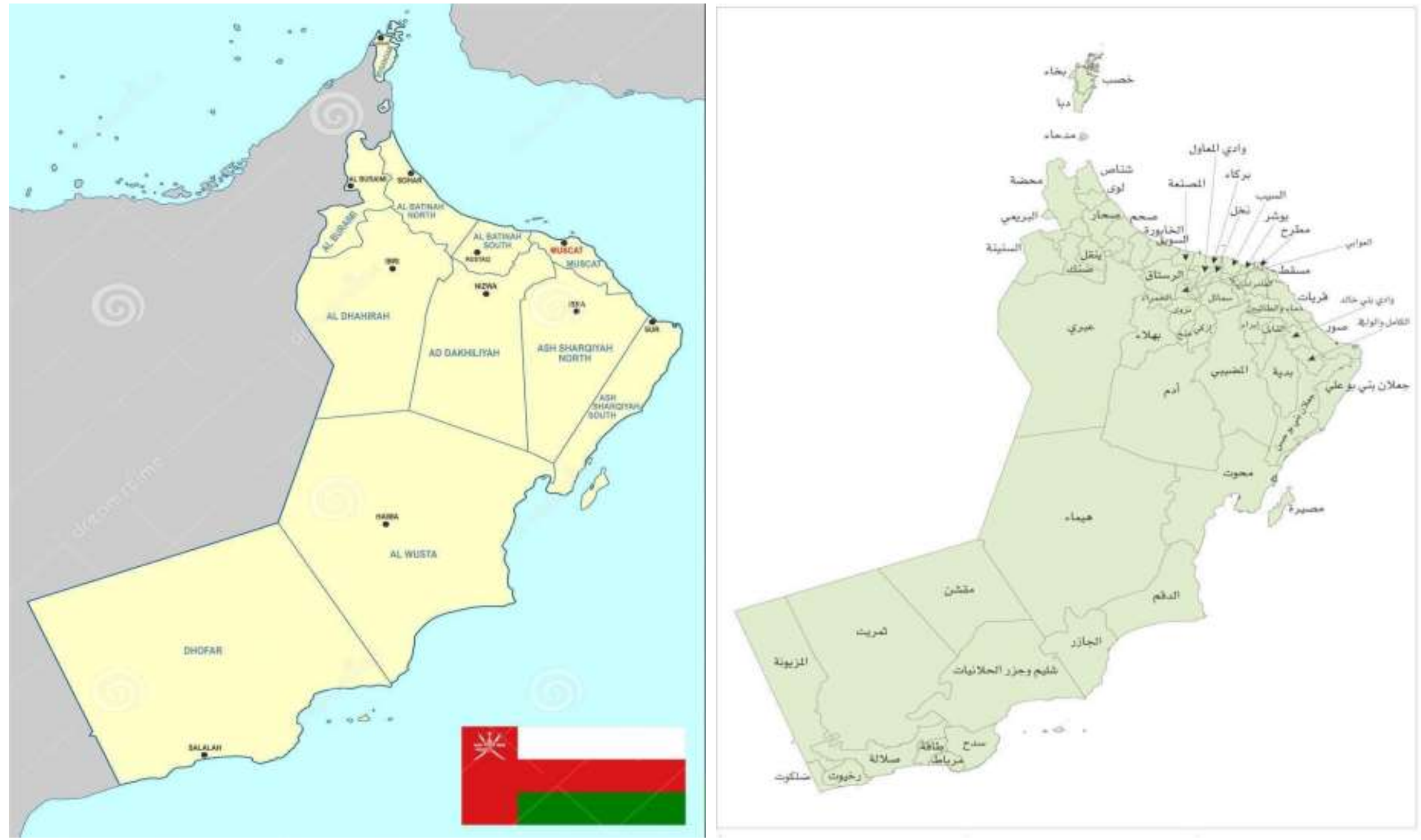


\section{Privatisation}

Until very recently, all utilities were in public hands. However, in part because of pressures caused by recent low oil prices, a ballooning state budget following the 2011 protests and the need for further investment as part of Oman's economic diversification campaign, there has been a considerable relaxation of ownership rules. The recent arrival of privatisation of utilities in Oman, albeit only in the electricity sector thus far (Nama Holding Announces OETC Privatization, 2019), and new privatisation and public-private partnership laws decreed in 2019, means that, not only will significant sums of money be raised from the part sale of (generally minority) stakes in these utilities but that these strategic assets are essentially being decentralised, at least in part, to the market. This is clearly designed to drive efficiencies in terms of production and distribution, thereby reducing direct costs to the state as Oman begins to wean itself off subsidies. This move will also reduce the direct burden on the state and will ultimately rest greater power with the market itself. If the market is making more decisions and the utilities are less cushioned by government involvement then this is clearly a form of decentralisation. It remains limited but is clearly part of wider moves to de-risk, drive efficiency and gather greater input into government activities. Yet, by maintaining considerable stakes in these new companies, the state itself will be able to maintain control where needed.

\section{New Authorities}

In the past decade in particular, Oman has followed other Gulf States in the creation of free zones and special economic authorities. These entities have extensive powers within their jurisdictions, including financial, taxation, customs, immigration and planning freedoms, vested in the hands of boards and governing councils of these new bodies. These new authorities, including developments in Sohar, Al Mazunah, Salalah, the Free Port and Special Economic Zone at Duqm, along with Knowledge Oasis Muscat, exhibit slightly different ownership and governance structures to each other but the State retains ultimate oversight. The umbrella organisation for the six Industrial Estates, the Public Establishment for Industrial Estates (today known as Madayn), established in 1993, reports directly to the Ministry of Commerce and Industry (Ministry of Legal Affairs, 2015). The Sohar Port and Freezone, meanwhile, is a 50:50 partnership between the Omani government and the Port of Rotterdam, and thus is more of a mirror of the privatisation strand above, yet with direct decentralisation of far more significant powers. These authorities, along with newer ones such as tanfeedh, which is responsible for economic diversification and has extensive monitoring powers, means that there is increasing fragmentation of control in terms of implementation of the five year plans and visions. This leads to ministries and other agencies 
becoming, to an extent, decentralised hubs, emanating from a higher level of authority - in most cases the Supreme Planning Council (Calabrese, 2018).

These new authorities and zones are clearly a form of decentralisation of power in technical terms and yet a centralisation in political terms. Through the proliferation of bureaucracies - whether nominally responsible to a ministry, to the Supreme Council for Planning (chaired by the Sultan) (Sultanate of Oman Supreme Council for Planning, 2020), or directly to the Diwan itself - the Sultanate is able to maintain control where needed. It is also able to decentralise power, often in quite an extensive manner down to a very localised level but without the need for truly local representation thereby delivering both national and local benefits through a technocratic process

\section{Devolution within Existing Structures}

It would perhaps be easy to begin to confuse decentralisation in Oman with the way in which Ministries in Oman, especially in recent years, have opened Ministry branches in specific regions and have moved some sub-units outside of Muscat. This is especially the case with fisheries, agriculture and water. This tradition, and indeed acceleration of this process, can be explained both through the need to move these highly paid and esteemed jobs outside of Muscat to spread opportunity and prevent the brain drain to the capital. This helps to ensure the regime's legitimacy through the rentier bargain but also because these more technical areas also need input in various forms from the people they serve, enabling the state to better meet local needs. There has also been a recent, complimnetary, move to decentralise decision-making to the frontlines of service delivery as well.

Healthcare decentralisation has been developed since the mid-1990s, from a previously heavilycentralised ministry. In June 2016, for example, the Ministry of Health announced further developments in decentralisation of healthcare decision making. Over this period, individual wilayats became responsible for the management of regional health services and ten regional health directorates were established with control over facilities and healthcare finances in their areas. In addition some 2,000 hospitals have been given self-governance (Oxford Business Group, 2017, p. 239). Indeed, a World Health Organisation (WHO) report as early as 2006 comments on some of these processes:

Development of strategic planning at the central level and regional planning using a participative approach; the use of Wilayat (district) Team Problem Solving (DTPS) approach to train the local functionaries and initiate a planning approach at the district level; all helped in improving plan formulation, monitoring and implementation (World Health Organisation, 2006). 
Reporting directly on decentralisation processes driven by the Omani Ministry of Health, the WHO further states:

The Ministry has extended its decentralization mission further by embarking on a hospital autonomy initiative (which also entails a re-engineering of hospital management, training of Omani physicians in hospital management, development of hospital performance indicators), and establishing Wilayat Health Directorates in several regions (led by family physicians). IT-based hospital information management systems in hospitals and health centers are being further strengthened eventually to be nationally linked to realize the vision of e-governance (World Health Organisation, 2006).

These quotes demonstrate that there is a clearly ambitious and well thought through process of decentralisation that has been long-established in the government healthcare sector, all of which has been in conjunction with various international organisations, including WHO, UNICEF and the World Bank (See The World Bank, 2001, 2006). What is particularly interesting about the decentralisation away from the Ministry of Health is that this extends down to the Governorate and wilayat levels and yet, outside of Dhofar and Muscat, the Governorates and wilayats are still structured to report to the Ministry of Regional Municipalities and Water Resources. This, upon closer inspection of their organigramme, demonstrates an entire pillar at the Ministry level dealing with these new healthcare responsibilities that have supposedly been devolved to the very local level (Ministry of Regional Municipalities and Water Resources: Organisational Structure, n.d.).

Oman has also used decentralisation as a tool to drive efficiency improvements in the educational sphere, in the hope of encouraging creative, localised, problem-solving and less waste of resources. The Ministry of Education (MoE) has therefore sought to involve teachers in the decentralisation process to push some decision-making that, more logically, should have been taken within individual schools. Interestingly, this has become somewhat contested. For instance, it has been notable that teachers have increasingly been at the forefront of some of recent demonstrations in the Sultanate. This seems partly to be driven by a mix of ideological influence and partly by demands for more resources. There have also been some criticisms of the failure of the MoE to recognise the need to provide school principals with the tools to manage increased staff involvement in governance within what is a largely centralised and hierarchical system (Westrick and Miske, 2009).

It is clear from these two examples that this form of decentralisation within existing structures is a highly technocratic process, primarily in service-focused areas, with complex and highly 
professional needs that are less amenable to fully-centralised control, due to issues of response and detail. Even in this process, though ministries still play a crucial role and the decentralisation is often partial and ongoing, this form of decentraliation faces clear challenges in terms of training, clarity of purpose and limits, leadership and wider culture within traditionally hierarchical structures.

\section{The Challenges of Decentralisation}

The challenges faced by the Sultanate in terms of efficiency, legitimacy and managing change, as well as its centralised recent history, help to illustrate why the country has opted for a controlledbybrid-decentralised model. This explains why, despite considerable outside influence, Qaboos' pragmatism evolved a model which is better suited for the Omani experience, and therefore does not align well with traditional definitions and understandings espoused by international organisations and donors. This means that the challenges facing the decentralisation process in Oman are somewhat different to those facing these processes elsewhere in the region.

Resistance to decentralisation is difficult in a system such as Oman's, in which bureaucratic agency is somewhat constrained. This reality does not negate the continuation of bureaucratic politics that can hamper decentralisation moves, or resistance from individuals within the system itself but this is not publically expressed. Ultimately, if decentralisation is decreed, due to continuing oversight mechanisms, it will be implemented. It is clear that part of the response to the protests of 2011 was the need to create more jobs. The only way to do this quickly was to create government jobs, meaning that some elements of decentralisation became centralising projects, partly because of the importance of a response, the creation of new jobs but also because of the need for speed in this process, which could only really be driven centrally.

There is relatively little difference in the ways in which decentralisation has occurred in most regions in the country. There are, however, some exceptions to this rule. Muscat Municipality, has historically been privileged with greater powers and authority than other municipalities. Muscat is joined in its wider powers by Dhofar Municipality, established in 1971 (to co-ordinate development during the Dhofar War) (Worrall, 2014), which, confusingly, is actually the body for the whole governorate of Dhofar. Dhofar Municipality contains ten wilayats and also sits within the administrative structure of office of the Minister of State and Governor of Dhofar, who is within the Diwan (Dhofar Municipality, 2014). There have however been deliberate attempts to decentralise evenly, while also using central ministries and resources to keep some measure of control over the process. Thus, aside from the usual and expected variations and minor difficulties at the highly local (micro) level that are only to be expected, because decentralisation is driven and 
monitored by the centre decentralisation tends to be rolled out in a more uniform manner than perhaps seen elsewhere and lessons learned in the showcase municipalities of Muscat and Dhofar are widely disseminated.

It is clear, however, that there are a number of administrative and technical challenges to decentralisation; this is, in part, a reason for the development of Oman's controlled-bybriddecentralisation model. The propensity to reach for shura to reach consensus and if this is impossible to defer or refer to another authority is a feature of the system - the system therefore recognises both the necessity for local action and that sometimes oversight is necessary to maintain harmony. Challenges to decentralisation are partly related to mindsets within the system. Shifting from a heavily centralised structure to even limited forms of decentralisation brings challenges in terms of implementation. Oman's tradition of shura holds promise for more deliberative forms of problem solving at a local level but this can at times clash with a propensity to defer decisions, try to reach consensus when immediate action is required and to refer decisions upwards. This culture holds especially true in more classical senses of decentralisation, such as through bureaucracies or in municipality and ministry settings.

This is clearly improving as structures become more embedded, patterns of responsibility evolve, and as new generations of increasingly well-educated officials are recruited and promoted. However, there does remain an issue with the skill sets and enabling environments within decentralised structures, particularly at the local level, meaning staff are not confident enough in taking full responsibility for decision-making and local problem solving. These remaining challenges in terms of training, mindsets and embedded path dependencies which despite new structures continue to be attuned to older patterns of responsibility and resource allocation, which are centrally-structured by the Ministries and which still privilege some areas over others. These issues are, however, amenable to change as training improves and as new forms of e-government emerge to further drive efficiencies. ${ }^{1}$

The extensive use of consultants and technology by the Omani state is both a blessing and a curse. Behaviours are modelled, systems are improving and as the country moves government services online in complex and innovative ways, this can enable decentralisation of service provision quite well. Omanis, at least anecdotally, are reporting greater levels of satisfaction with government service provision; for instance, local police stations can now renew passports on the spot. Consultants and technology combined have been formidable tools for the state to drive forward

\footnotetext{
${ }^{1}$ Oman has invested heavily in e-government initiatives. These are often initially basic, but have improved and spread rapidly over the past decade, bringing some real benefits. But there are reports of issues and a lack of consultation in the development of some of these initiatives. See: (Al-Mamari, Corbitt and Gekara, 2015).
} 
change and contribute to clear progress narratives. All of which is immensely positive for both citizens and the government in terms of meeting its aims and objectives. At the same time, these technocratic responses mean that decentralisation is depoliticised, decision-making on adoption of strategies remains centralised and consultants dis-empower, to a degree, those further down the systems which are designed to facilitate technocratic solutions rather than social or political solutions, which may in fact be more legitimate and indeed effective. This may well be in part by design; the technocratisation can outsource some decision-making, meaning a form of horizontal referral of a problem; just like when the deferral of a decision at a local level or its referral upwards can also be important tools as part of processes of ensuring harmony within organisations. There remain clear problems with the quality of training and leadership processes, as well as support systems, all of which can encourage delegation within decentralised structures and are therefore likely to continue to pose issues for ongoing decentralisation processes.

\section{Conclusion}

Decentralisation in the Sultanate serves two immediate purposes - efficiency and legitimacy - both of which are difficult to measure given the lack of data available and that the scale of decentralisation has been relatively limited, albeit growing over the past two decades. It is therefore likely to be some time before a complete picture of the contours of decentralisation emerges, let alone a true idea of whether it has served these two immediate objectives. Yet, there has been clear progress and some benefits derived from decentralisation, especially when it comes to bringing government services closer to citizens.

It is clear that, while decentralisation in its quadripartite form taken in Oman does aim to create spending efficiencies in fiscally straightened times and to create a diversified and more responsive economic and public service system, in many ways the decentralisation that has occurred is actually more concerned with balancing multiple economic and political needs. In many ways, the four elements of decentralisation in Oman are really more about politics and maintaining the ruling system.

What is emerging is a complex pattern of controlled-hybrid-decentralisation within a strong central state. It is in many ways more about a re-interpretation of centralisation than it is a true process of decentralisation. The Sultan still retains ultimate authority and webs of control combine all four elements of the decentralisation process. This means that, while decentralisation is supposed to enhance core elements of the country's economic diversification, government efficiency and value for money agendas in straightened times, in Oman it is a tightly controlled and reversible form of decentralisation - apolitical and highly technocratic in nature. Ultimately, in order to understand 
decentralisation in Oman, one must accept that it is the result of competing pressures and important paradoxes.

Firstly, the country must become more efficient if it is to be able to fund the services it needs and facilitate the economic diversification that is so crucial. Secondly, the country is strongly influenced by Western economic knowledge ${ }^{2}$ and experts who tend to be neoliberal in outlook. This orthodoxy promotes decentralisation as a key tool underpinning notions of modernity and economic efficiency. Thirdly, there are strong path dependencies towards centralisation and clear logics that exist alongside vulnerabilities in following extensive political decentralisation processes in particular. Fourthly, despite the existence of a strong central state, local Omani traditions still emphasise consensus building, consultation and inclusion, thereby offering potentially ideal conditions for increased decentralisation to flourish and achieve its objectives.

Thus alongside the four forms of decentralisation, there are two notions of decentralisation in Oman. The first is that the Sultan ultimately controls and simply bequeaths power to someone else, making decentralisation dependent upon its being effective in achieving its objectives. The second is a tradition of engagement that means that decentralisation is linked to responsiveness, consultation and discussion - forms of decentralisation that are already inherent in the system and in society. In this way, decentralisation is not only about the devolution of power to regions or experts but is also about the gathering of viewpoints locally and their representation at the centre, allowing the central state to respond to demands away from the centre in a coordinated manner. What emerges is a hybrid, not only in terms of the forms of decentralisation but also in the purposes of decentralisation that are both technocratic and designed to represent central power locally, allowing a direct channel of communication to the central state to respond to local concerns. ${ }^{3}$ It is about bringing government closer to the people, just often in a different way to the political decentralisation seen in the West.

Increasingly, there is a distinction between a highly centralised state in terms of key ministries and a degree of decentralisation in others. The extent to which the events of 2011 and the severe budgetary constraints following the collapse of oil prices in 2015/16 have altered decentralisation patterns remains to be fully seen, especially as these problems have now been compounded by the

\footnotetext{
2 One must here note the involvement of Malaysian experts from the Malaysian government's Performance Management and Delivery Unit within the Tanfeedh economic diversification process in the Sultanate. See: (Tanfeedh Economic Initiatives to Aid Oman's Diversification Drive, 2019).

3 This may be seen as similar to processes in authoritarian regimes elsewhere where information is extracted but no power is devolved, see for example: On China - (Truex, 2017); On Latin America - (Geddes, 1994); On the Middle East - (Blaydes, 2010). The argument here is more nuanced in that, yes the Omani state wishes to do both of those things, but that power is beginning to trickle down and, given its history and culture of shura consultation and processes, means that the extraction of information is a two way process of shaping policy, however partial and informalised that may be.
} 
Covid-19 Pandemic and the further collapse of oil prices in 2020. However, is clear that new and different people and approaches are being brought into the conversation and that the Omani state is able to pursue decentralisation and increased participation in a piecemeal manner. In sum, decentralisation in Oman is the outcome of these competing pressures and will continue to be a balancing act between them.

In this sense, it is not simply a question of comparing Middle Eastern decentralisation processes between Republican, Authoritarian and Monarchical systems of rule but is really about questioning the frames of decentralisation that are used in Western democratic contexts and the extent to which they retain utility in understanding logics and processes of decentralisation in the Omani context. Even Western technocratic, as opposed to political, understandings of decentralisation that have impacted thinking and processes in Oman, clearly focus attention on problem-solving approaches and thus bypassing the political necessities and path dependencies in Oman, which both constrains and enables decentralisation in what remains a highly centralised polity. Oman may be a monarchy, like Jordan and Morocco, but both of those countries have active parliaments and are much more exposed to the whims of donors than the Sultanate. Oman has been able to embrace elements of decentralisation where it believes it will assist in its goals and still maintain the core of its centralised structure, yet in a hybridised and restructured manner both fitting with neoliberal dynamics and at the same time both co-opting them to preserve the core of the ruling coalition (Valeri, 2013) and the absolute authority of the Sultan. Under this approach, decentralisation both reinforces centralised power and seemingly offers benefits that assist in the maintenance of economic development and growth, underpinning the wider ruling bargain.

Naturally, it remains to be seen whether this approach will change under the rule of Sultan Haitham bin Tariq, but immediate change seems unlikely. In Oman, decentralisation is used to re-enforce centralisation; therefore decentralisation best practices must take into account these overarching realities if they are to succeed. Since the objectives of decentralisation are not purely efficiencybased, technocratic solutions must also be a part of both local culture and the political realities of the Sultanate. 


\section{References}

Dhofar Municipality (2014) About Dhofar Municipality [Online] Available at: http://www.dm.gov.om/Pages.aspx?PGID=1\&PAID=2\&MID=7.

Al-Mamari, Q., Corbitt, B. and Gekara, V. (2015) 'E-Government Adoption and Implementation in Oman: A Government Perspective', in Haidar, A. (ed.) Business Technologies in Contemporary Organizations: Adoption, Assimilation, and Institutionalization. Hershey, PA: Business Science Reference, pp. 263-287.

Blaydes, L. (2010) Elections and Distributive Politics in Mubarak's Egypt. Cambridge: Cambridge University Press.

Calabrese, J. (2018) Oman's Transition to a Post-Oil Economy: Arching Toward Asia, Middle East Institute. Available at: https://www.mei.edu/publications/omans-transition-post-oil-economy-archingtoward-asia.

Geddes, B. (1994) Politician's Dilemma: Building State Capacity in Latin America. Berkeley: Univ of California Press.

Ghubash, H. (2006) Oman - The Islamic Democratic Tradition. Routledge: London.

Ivanyna, M. and Shah, A. (2012) 'How Close Is Your Government to Its People? Worldwide Indicators on Localization and Decentralization,' Worldwide Indicators on Localization and Decentralization (July 1, 2012). World Bank Policy Research Working Paper, (6138).

Ministry of Legal Affairs (2015) 'Royal Decree No. 32/2015 Promulgating the System (Law) of the Public Establishment for Industrial Estates (PEIE)', Official Gazette, 1108. Available at: https://madayn.om/MadaynDocuments/Madayn/Legislations/Legislation_Royal_Decree.pdf.

Ministry of Regional Municipalities and Water Resources: Organisational Structure (n.d.). Available at: https://mrmwr.gov.om/en/web/mrmwr/organization-structure.

Muscat Municipality: Brief History (n.d.). Available at:

https://www.mm.gov.om/Page.aspx?PAID=1\#Details\&MID=6\&PGID=112\&Slide=True.

Nama Holding Announces OETC Privatization (2019) Oman News Agency. Available at: https://omannews.gov.om/description_bkp/ArtMID/867/ArticleID/4906/Nama-HoldingAnnounces-OETC-Privatization.

Oxford Business Group (2017) The Report: Oman 2017. Oxford: The Oxford Business Group.

Rabi, U. (2002) 'Majlis Al-Shura and Majlis al-Dawla: Weaving Old Practices and New Realities in the Process of State Formation in Oman,' Middle Eastern Studies. Taylor \& Francis, 38(4), pp. $41-$ 50 .

Sultanate of Oman Supreme Council for Planning. (2020) About SCP [Online]. Available at: https://www.scp.gov.om/en/Page.aspx?I=6.

Oxford Business Group (2019) Tanfeedh Economic Initiatives to Aid Oman's Diversification Drive [Online]. Available at: https://oxfordbusinessgroup.com/analysis/developmental-catalyst-shortterm-successes-tanfeedh-suggest-lasting-legacy-sultanate $\% \mathrm{E} 2 \% 80 \% 99 \mathrm{~s}$.

The World Bank (2001) Sultanate of Oman: Cost Effectiveness Review of the Health Sector (Main Report). 
The World Bank (2006) Sultanate of Oman: Enhancing Revenues for Health Services: Issues and Options.

Treichel, V. and Mansur, A. S. (1999) Oman Beyond the Oil Horizon; Policies Toward Sustainable Growth. International Monetary Fund.

Truex, R. (2017) 'Consultative Authoritarianism and Its Limits', Comparative Political Studies, 50(3), pp. 329-361.

United Cities and Local Government and World Bank (2008) Decentralization and Local Democracy in the World: First Global Report by United Cities and Local Governments 2008. The World Bank (World Bank Publications, 2609). Available at:

https://ideas.repec.org/b/wbk/wbpubs/2609.html.

Valeri, M. (2013) 'Domesticating Local Elites. Sheikhs, Walis and State-Building Under Sultan Qaboos', in Whippel, S. (ed.) Regionalizing Oman. London: Springer, pp. 267-278.

Westrick, J. M. and Miske, S. J. (2009) 'Leadership for Innovative Omani Schools in the 21st Century: Transforming Principal Identity through Culturally Contextualised Training', in Wiseman, A. (ed.) Educational Leadership: Global Contexts and International Comparisons (International Perspectives on Education and Society, Volume 11). Bingley: Emerald Group Publishing, pp. 1-47.

World Health Organization (2006) Health Systems Profile Oman 2006. World Health Organization, p. 28. Available at: https://apps.who.int/medicinedocs/documents/s17304e/s17304e.pdf.

Worrall, J. (2012) 'Oman: The "Forgotten" Corner of the Arab Spring', Middle East Policy, 19(3), pp. 98-115.

Worrall, J. (2014) Statebuilding and Counterinsurgency in Oman: Political, Military and Diplomatic Relations at the End of Empire. London: IB Tauris.

Worrall, J. (2015) 'Protest and Reform: The Arab Spring in Oman', in Sidiki, L. (ed.) Routledge Handbook of the Arab Spring: Rethinking Democratization. London: Routledge, pp. 518-528.

Zsamboki, K. and Bell, M. (1997) 'Local Self-Government in Central and Eastern Europe: Decentralization or Deconcentration?', Environment and Planning C: Government and Policy. SAGE Publications Sage UK: London, England, 15(2), pp. 177-186. 